\title{
Radiolabeled Peptides for Cancer Imaging and Therapy: From Bench-to-Bedside
}

\author{
Rosalba Mansi and Melpomeni Fani*
}

\begin{abstract}
Radiolabeled peptides can deliver radiation selectively to tumors via targeting peptide receptors that are overexpressed on the surface of cancer cells. The radiation is used either for detection (imaging) or for destruction (therapy) of these tumors. The Division of Radiopharmaceutical Chemistry at the University Hospital Basel has conducted pioneering work on the development of peptide-based radiopharmaceuticals. Our research covers the entire spectrum of such developments, from bench-to-bedside, and it is illustrated in this article by selective cases.
\end{abstract}

Keywords: Clinical translation · Exendin-4 Minigastrin · Somatostatin · Theranostics

\section{Introduction}

The development of selective targeting strategies for tumor detection and therapy is of outmost importance for precision medicine. Peptides can be chemically tuned to target cell-surface receptors that are expressed in very high density on cancer cells, compared to their relatively low density in physiological organs. This offers the possibility of accumulation of radiolabeled peptides on the diseased tissue with minimal accumulation to normal tissues. G-protein coupled receptors (GPCRs) are, for example, a rich source of potential targets as their overexpression is linked to numerous human malignancies.

The medical application of a radiolabeled peptide is defined by the radionuclide (Table 1 ); $\gamma$-emitters are used for Single Photon Emission Computed Tomography (SPECT), positron $\left(\beta^{+}\right)$-emitters are used for Positron Emission Tomography (PET), while radionuclides emitting $\beta^{-}$-particles or $\alpha$-particles or Auger electrons, able to destruct cells, are used for therapy (Peptide Receptor Radionuclide Therapy, PRRT). The vast majority of the clinically relevant radionuclides are radiometals. The radiometal is incorporated into the peptide moiety via a chelator forming a stable complex (Fig. 1). For example, a wide range of (radio)metals in the oxidation state $3+$, such as Lu, Y, Ga, In (and many more), form stable complexes with the octadentate chelator 1,4,7,10-tetraaza-1,4,7,10-tetraacetic acid (DOTA). Other chelators are more (radio)metal-selective, such as the hexadendate 1,4,7-triazacyclononane,1-glutaric acid-4,7-acetic acid (NODAGA) used for $\mathrm{Ga}^{3+}$ or $\mathrm{Cu}^{2+}$.

The similar chemical properties of many radiometals allow great flexibility on the design and applications and offer a unique feature on this type of radiopharmaceuticals. The same peptidechelator conjugate can be labeled, alternatively, with radionuclides suitable for imaging or for therapy (Fig. 1). Such pharmaceuticals, blending diagnostics and therapeutics properties, are named 'theranostics' or 'radiotheranostics'. Radiotheranostics are used for performing diagnoses and therapies, allow patients' stratification, but also predict and monitor the efficacy of targeted therapies. Radiotheranostics are very powerful tools for precision medicine and their application in oncology is expanding rapidly.

The radionuclides and chelators discussed herein are summarized in Table 1 and all peptide analogs are presented in Table 2.

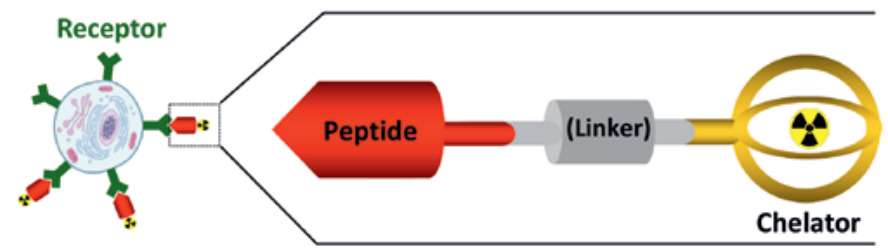

Fig. 1. Classical design of peptide-based radiopharmaceuticals targeting receptors overexpressed on the surface of tumor cells. They consist of: a) the peptide responsible for binding to the receptor of interest, b) a chelator forming a stable complex with the radionuclide and c) the radionuclide that allows either imaging ( $\gamma$ - or $\beta^{+}$-emitter) or therapy $\left(\beta^{-}, \alpha\right.$ or Auger electron emitter). Between the peptide and the chelator a linker is often introduced either for reserving the affinity of the peptide for the receptor or as a pharmacokinetic modifier.

\section{Somatostatin-based Radiopharmaceuticals}

Radiolabeled analogs of the hormone somatostatin are used for targeting somatostatin receptors (SST), especially of subtype 2 (SST2), which are overexpressed in neuroendocrine tumors (NETs). The octreotide analogs [DOTA, Tyr ${ }^{3}$ ]octreotide (DOTATOC) and [DOTA, $\mathrm{Tyr}^{3}, \mathrm{Thr}^{8}$ ]octreotide (DOTA-TATE) labeled with ${ }^{68} \mathrm{Ga}$ are used for PET imaging; when labeled with ${ }^{177} \mathrm{Lu}$ or ${ }^{90} \mathrm{Y}\left({ }^{177} \mathrm{Lu} /{ }^{90} \mathrm{Y}\right.$-DOTA-TOC and ${ }^{177} \mathrm{Lu}$-DOTA-TATE (Lutathera $\left.{ }^{\circledR}\right)$ ), they are used for therapy. These are agonists, which upon binding to the receptor induce internalization of the receptor-peptide complex. Internalization was thought to be of high importance for high and long-lasting tumor uptake, thus for high image contrast and effective treatment.

Inversion of chirality at positions 1 and 2 of the octreotide family converted an agonist into a potent antagonist, ${ }^{[1]}$ while other structural features contributed to antagonistic properties.[2] The groups of Maecke (University Hospital Basel), Rivier (Salk Institute, La Jolla) and Reubi (University of Bern), were the first to develop radiolabeled SST antagonists. ${ }^{[3,4]}$ We provided the first clinical evidence that imaging with SST2 antagonists may be superior to agonists. ${ }^{[5]}$ The antagonist ${ }^{111}$ In-DOTA-BASS showed higher tumor uptake and lower uptake in normal organs, consequently higher tumor detection rate, than the agonist 
Table 1. Selected radiometals and chelating systems discussed in the article.

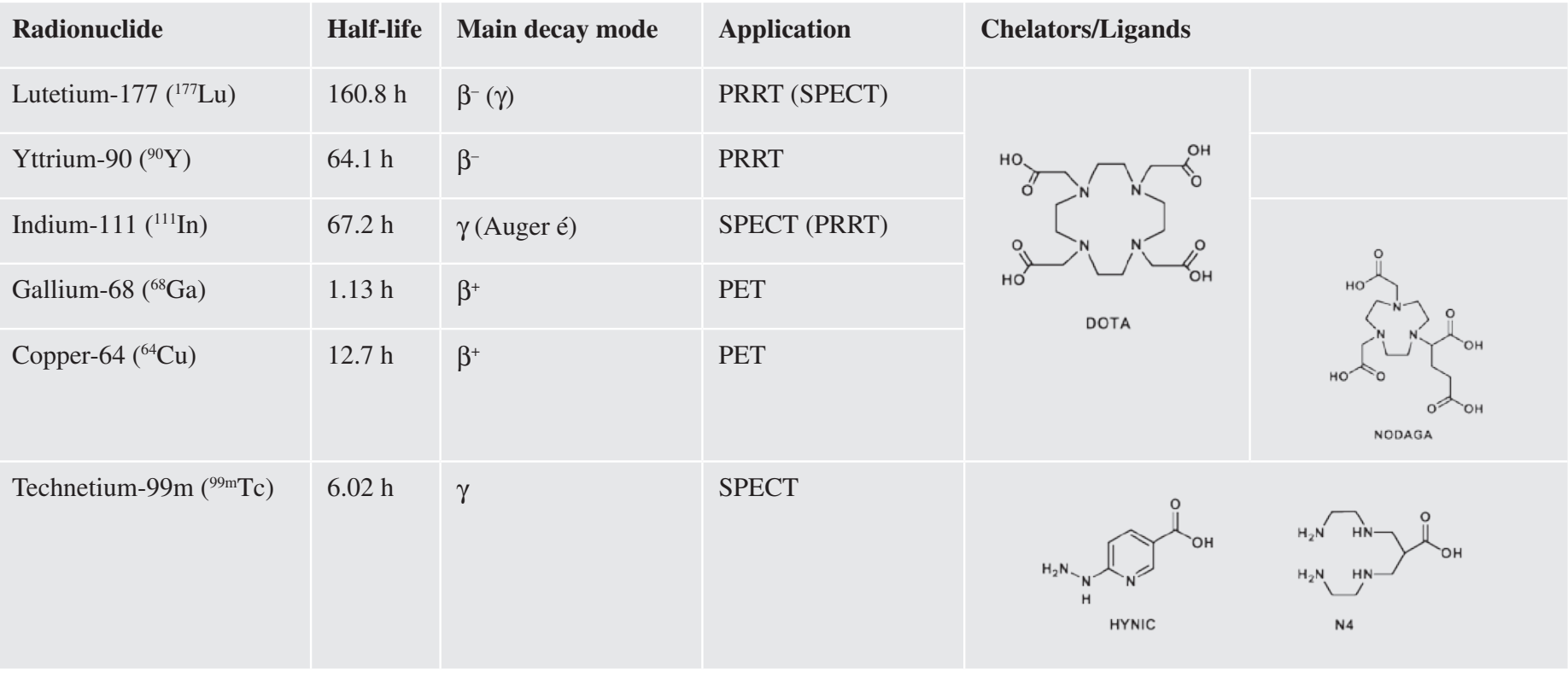

PRRT: Peptide Receptor Radionuclide Therapy; SPECT: Single Photon Emission Computed Tomography; PET: Positron Emission Tomography; DOTA: 1,4,7,10-tetraazacyclododecane-1,4,7,10-tetraacetic acid; NODAGA: 1,4,7-triazacyclononane,1-glutaric acid-4,7-acetic acid; HYNIC: hydrazinonicotinamide; N4: 6-carboxy-1,4,8,11-tetraazaundecane

Table 2. Amino acid sequence of the peptides reported in the article.

\begin{tabular}{|c|c|}
\hline Code & Chemical Structure \\
\hline \multicolumn{2}{|c|}{ Somatostatin receptor agonists } \\
\hline $\mathrm{OC}$ & D-Phe-cyclo(Cys-Phe-D-Trp-Lys-Thr-Cys)Thr(ol) \\
\hline TOC & D-Phe-cyclo(Cys-Tyr-D-Trp-Lys-Thr-Cys)Thr(ol) \\
\hline TATE & D-Phe-cyclo(Cys-Tyr-D-Trp-Lys-Thr-Cys)Thr \\
\hline \multicolumn{2}{|c|}{ Somatostatin receptor antagonists } \\
\hline BASS & p-NO $\mathrm{N}_{2}$-Phe-cyclo(D-Cys-Tyr-D-Trp-Lys-Thr-Cys)D-Tyr- $\mathrm{NH}_{2}$ \\
\hline SS01 & p-Cl-Phe-cyclo(D-Cys-Tyr-D-Trp-Lys-Thr-Cys)D-Tyr-NH ${ }_{2}$ \\
\hline LM3 & p-Cl-Phe-cyclo(D-Cys-Tyr-D-Aph(Cbm)-Lys-Thr-Cys)D-Tyr- $\mathrm{NH}_{2}$ \\
\hline JR10 & p-NO ${ }_{2}$-Phe-cyclo(D-Cys-Tyr-D-Aph(Cbm)-Lys-Thr-Cys)D-Tyr-NH ${ }_{2}$ \\
\hline JR11 & p-Cl-Phe-cyclo(D-Cys-Aph(Hor)-D-Aph(Cbm)-Lys-Thr-Cys]-D-Tyr-NH ${ }_{2}$ \\
\hline \multicolumn{2}{|c|}{ Minigastrin analogs } \\
\hline MG0 & D-Glu-Glu-Glu-Glu-Glu-Glu-Ala-Tyr-Gly-Trp-Met-Asp-Phe-NH ${ }_{2}$ \\
\hline MG11 & D-Glu-Ala-Tyr-Gly-Trp-Met-Asp-Phe- $\mathrm{NH}_{2}$ \\
\hline PP-F10 & D-Gln-D-Gln-D-Gln-D-Gln-D-Gln-D-Gln-Ala-Tyr-Gly-Trp-Met-Asp-Phe-NH 2 \\
\hline PP-F11 & D-Glu-D-Glu-D-Glu-D-Glu-D-Glu-D-Glu-Ala-Tyr-Gly-Trp-Met-Asp-Phe-NH 2 \\
\hline PP-F11N & D-Glu-D-Glu-D-Glu-D-Glu-D-Glu-D-Glu-Ala-Tyr-Gly-Trp-Nle-Asp-Phe-NH ${ }_{2}$ \\
\hline
\end{tabular}

$\mathrm{Aph}(\mathrm{Hor})=$ 4-amino-L-hydroorotyl-phenylalanine; D-Aph $(\mathrm{Cbm})=\mathrm{D}-4$-amino-carbamoyl-phenylalanine

${ }^{111} \mathrm{In}$-DTPA-octreotide (OctreoScan $\left.{ }^{\mathrm{TM}}\right)$. In vitro autoradiography in human SST2-positive tumor sections revealed that the therapeutic counterpart ${ }^{177} \mathrm{Lu}-\mathrm{DOTA}-\mathrm{BASS}$ had higher binding capacity than ${ }^{177}$ Lu-DOTA-TATE, ${ }^{6]}$ while its long tumor residence time in a SST2-expressing animal model indicated that this new class of compounds is of relevance for therapy. ${ }^{[7]}$
Radiolabeled SST2 antagonists with improved affinity were further developed by introducing amine bond-rich moieties (carbamoyl functionalities) for favorable receptor recognition and by enhancing potential intra- and inter-molecular hydrogen bonding (urea functionalities) for structural stabilization. ${ }^{[8,9]}$ This work revealed an unexpected sensitivity of the antagonists to chemical 
modification at their N-terminal. Using different chelators and radiometals for PET imaging, like ${ }^{68} \mathrm{Ga}$ and ${ }^{64} \mathrm{Cu}$, in combination with the new SST2-antagonist LM3, we demonstrated that the chelate defines affinity and pharmacokinetics in this class of radiopharmaceuticals. ${ }^{[9]}$ This work illustrated that NODAGAconjugation was superior to the widely used DOTA-conjugation for ${ }^{68} \mathrm{Ga}$-PET tracers and to common chelating systems for ${ }^{64} \mathrm{Cu}-$ PET tracers. ${ }^{[9]}$

In a more comprehensive study, three different SST2antagonists, LM3, JR10 and JR11, were conjugated to the chelators DOTA and NODAGA and complexed with various (radio) metals, such as $\mathrm{In}^{3+}, \mathrm{Y}^{3+}, \mathrm{Lu}^{3+}, \mathrm{Cu}^{2+}$ and $\mathrm{Ga}^{3+} \cdot{ }^{[8]}$ To our surprise, all Ga-DOTA analogs were the least affine - up to 60 times lower than the respective Y-DOTA, Lu-DOTA or In-DOTA counterparts, contrary to what was known for the agonists. Interestingly, substitution of DOTA by NODAGA increased massively the binding affinity of all Ga-NODAGA antagonists. The most important findings came from the in vivo preclinical comparison of JR11 with the state-of-the-art agonist DOTA-TATE, in favor of the antagonist: (a) ${ }^{68} \mathrm{Ga}$-NODAGA-JR11 with a 6 -fold lower affinity than ${ }^{68} \mathrm{Ga}$-DOTA-TATE showed an up to 1.7 -fold higher tumor uptake, while also ${ }^{68} \mathrm{Ga}$-DOTA-JR 11 having a dramatically lower affinity $\left(\sim 150\right.$-fold) than ${ }^{68} \mathrm{Ga}$-DOTA-TATE showed a 1.3 -fold higher tumor uptake, ${ }^{[8]}$ (b) ${ }^{177} \mathrm{Lu}-\mathrm{DOTA}-J \mathrm{R} 11 \mathrm{had}$ a higher tumor residence time, compared to ${ }^{177} \mathrm{Lu}$-DOTA-TATE, with an impressive effect of its specific activity on the in vivo uptake and dosimetry (Fig. 2A) that might further improve the therapeutic index of PRRT. ${ }^{[10]}$

Overall, this work brought to light the theranostic pair ${ }^{177}$ Lu-DOTA-JR11/68 Ga-NODAGA-JR11 (known as ${ }^{177} \mathrm{Lu}-$ OPS201/ ${ }^{68} \mathrm{Ga}$-OPS202), which is currently the most favorable innovation in molecular imaging and radionuclide therapy of NETs. ${ }^{[11]}$ Our initial clinical studies showed that the antagonists versus the agonists may provide improved diagnostic sensitivity (showed by comparing ${ }^{68} \mathrm{Ga}-\mathrm{NODAGA}-J R 11$ versus ${ }^{68} \mathrm{Ga}$ DOTA-TOC $[12,13]$ ) and therapeutic efficacy (showed by comparing ${ }^{177} \mathrm{Lu}-D O T A-J R 11$ versus ${ }^{177} \mathrm{Lu}-D O T A-T A T E$ (Fig. 2B) ${ }^{[14]}$ ). ${ }^{177} \mathrm{Lu}-\mathrm{OPS} 201 /{ }^{68} \mathrm{Ga}-\mathrm{OPS} 202$ are under clinical evaluation by the pharmaceutical industry. The other theranostic pair from this series, ${ }^{177} \mathrm{Lu}$-DOTA-LM3 $/{ }^{68} \mathrm{Ga}-\mathrm{NODAGA}-\mathrm{LM} 3$, has been selected by different groups for clinical translation. ${ }^{[15,16]}$

Recently, we focused on developing ${ }^{99 \mathrm{~m}} \mathrm{Tc}$-based SST2 antagonists for SPECT imaging, given the fact that more than $70 \%$ of nuclear medicine procedures still use ${ }^{99 \mathrm{~m}} \mathrm{Tc}$. The well-established monodentate ligand hydrazinonicotinamide (HYNIC) was firstly conjugated to the antagonists SS01 and JR11 (similarly to [99m Tc] Tc-HYNIC-TOC (Tektrotyd)). [17] To our surprise, these conjugates massively lost their affinity for the SST2, which was possible to restore, to a different extent, by incorporating linkers of variable length and hydrophilicity, with aminohexanoic acid performing the best. ${ }^{[17]}$ In parallel, we utilized the alternative chelating system 6-carboxy-1,4,8,11-tetraazaundecane (N4), in combination with SS01 and LM3.[18] [ $\left.{ }^{99 \mathrm{~m}} \mathrm{Tc}\right] \mathrm{Tc}-\mathrm{N} 4-\mathrm{LM} 3$ ([ $\left.\left.{ }^{99 \mathrm{~m}} \mathrm{Tc}\right] \mathrm{Tc}-\mathrm{TECANT}-1\right)$ was selected, within the ERAPerMED project 'TECANT', to be the first ${ }^{99 \mathrm{~m}} \mathrm{Tc}$-labeled SST2 antagonist for clinical translation, due to its favorable in vivo properties preclinically. ${ }^{[18]}$

\section{Minigastrin-based Radiopharmaceuticals}

Cholecystokinin 2 (CCK2) receptor is a GPCR overexpressed in medullary thyroid cancer (MTC), among other tumor entities. The peptide hormone gastrin and the C-terminal 13-amino acid truncated form minigastrin (MG) have high affinity and specificity for the CCK2R. The C-terminal sequence Trp-Met-AspPhe- $\mathrm{NH}_{2}$ is crucial for receptor binding, with a characteristic sequence of penta-Glu at the N-terminal. Gastrin and minigastrin are particularly vulnerable to in vivo degradation by proteases. Radiolabeled stabilized forms of MG, such as MG0 (where Leu ${ }^{1}$ is substituted by $\mathrm{D}-\mathrm{Glu}^{1}$ ) showed encouraging tumor uptake in vivo, but unfavorably high accumulation in the kidneys that limited their use in PRRT.

In a series of ${ }^{111}$ In-DOTA-MG analogs, a reduced number of negative charges (reduced Glu residues) was correlated with lower kidney uptake, but also with lower tumor uptake and metabolic stability, as demonstrated by the analog where the glutamate sequence was removed (MG11). ${ }^{[19]}$ Our group introduced hydrophilic uncharged linkers of different lengths, such as PEG and D-amino acids (D-Ser, D-Gln or D-Glu) on DOTA conjugates of MG11.[20] Whereas increasing the number of PEG or D-Ser had rather limited impact on metabolic stability, the number of the D-Gln residues played an important role; the metabolic stability improved significantly from (D-Gln) ${ }_{2}$ to (D-Gln) ${ }_{6}$ (analog encoded PP-F10), while kidney uptake was reduced leading to improved tumor-to-kidney ratios. ${ }^{[20]}$ Further investigation on the role of stereochemistry at the $\mathrm{N}$-terminus by comparing (L-Glu) ${ }_{6}$ vs (D-Glu) (analog encoded PP-F11) showed that the biodistribution profile was more influenced by the secondary structure of the peptide (type II reverse turn conformation) than by the charge.[21] Our group participated in a systematic multicenter study supported by the European Cooperation in Science and Technology (COST) action BM0607 comparing improved minigastrin analogs developed by different groups in terms of affinity, metabolic stability and in vivo profile. The analog PP-F11 was the one chosen for clinical evaluation in MTC patients as imaging agent ( $\left.{ }^{111} \mathrm{In}-\mathrm{CP} 04\right)$ within the Bando ERA-net TRANSCAN EU project 'GRANT-T-MTC'.

In order to optimize CCK2R-targeting in vivo different approaches were further investigated: a) chemical stabilization, achieved by replacement of Met at PP-F11 that is susceptible
A

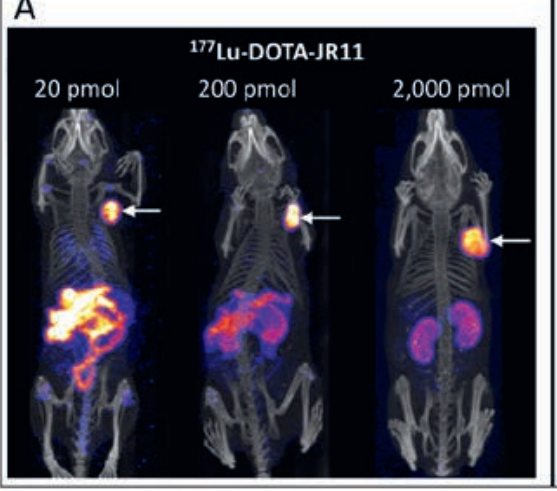

B

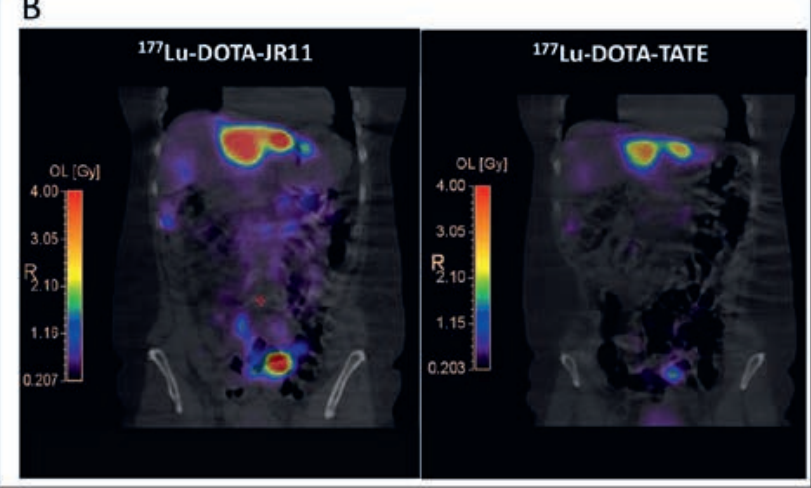

Fig. 2. A) Nano-SPECT/CT maximum-intensity-projection images of SST2-xenografts $4 \mathrm{~h}$ after administration of $20 \mathrm{pmol}, 200$ pmol and 2,000 pmol of ${ }^{177} \mathrm{Lu}-$ DOTA-JR11. Increase in peptide amount significantly decreased background activity, whereas tumor uptake (arrows) was not significantly affected. (Adapted from ref. [10]). B) Isodose curves of a patient after injection of ${ }^{177}$ Lu-DOTA-JR11 and after injection of ${ }^{177}$ Lu-DOTA-TATE, showing that the SST2-antagonists ${ }^{177} \mathrm{Lu}$ DOTA-JR11 delivered higher tumor dose (intensity of the color scale) than the agonist (Adapted from ref. [14]). 
to oxidation, by the non-oxidizing isosteric analogue norleucine (Nle) (analog encoded PP-F11N), b) in situ stabilization by the use of inhibitors of proteases responsible for the in vivo degradation and c) combination of both. ${ }^{[22]}$ The chemically stabilized ${ }^{177} \mathrm{Lu}-\mathrm{DOTA}-\mathrm{PP}-\mathrm{F} 11 \mathrm{~N}$ was compared to ${ }^{177} \mathrm{Lu}-\mathrm{DOTA}-\mathrm{MG} 11$ and ${ }^{177}$ Lu-DOTA-PP-F11, two analogs with varying stability, in CCK2R-expressing animal models. All three radiolabeled peptides were tested with and without the use of phosphoramidon and thiorphan, two protease inhibitors of the neutral endopeptidase (NEP). We concluded that chemical stabilization is preferable over in situ stabilization. ${ }^{\text {[2] }}$ Currently, we are evaluating ${ }^{177} \mathrm{Lu}-$ DOTA-PP-F11N in two clinical trials in patients with advanced MTC, also in combination with the NEP-1 inhibitor Sacubitril $\left(\right.$ Entresto $\left.^{\circledR}\right)$. Initial clinical data showed that ${ }^{177} \mathrm{Lu}$-DOTA-PPF11N accumulated specifically in MTC at a dose that is sufficient for a therapeutic approach, while the dose-limiting organ is most likely the stomach (Fig. 3A). ${ }^{[22,23]}$

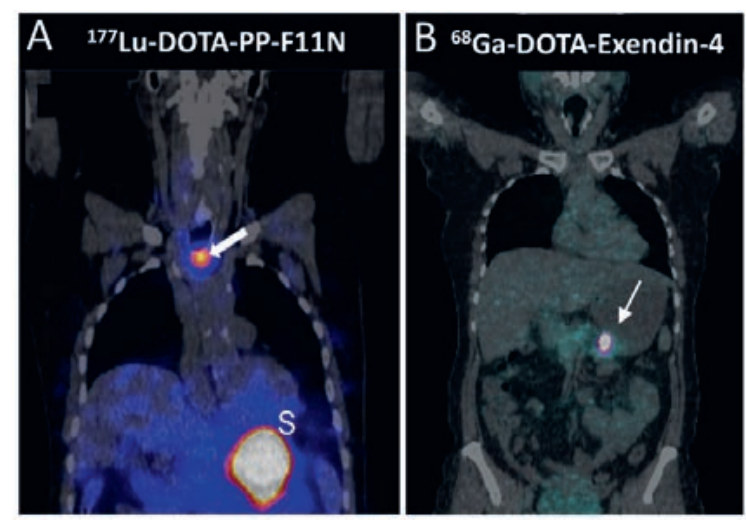

Fig. 3. A) Coronal SPECT/CT scan $24 \mathrm{~h}$ after injection of ${ }^{177} \mathrm{Lu}-\mathrm{PP}-\mathrm{F} 11 \mathrm{~N}$ visualized the tumor in a MTC patient (shown with the white arrow; $\mathrm{S}=$ stomach) (Courtesy of Dr. C. Rottenburger, University Hospital Basel). B) Coronal PET/CT image obtained $2.5 \mathrm{~h}$ after injection of $\left[\mathrm{Nle}^{14}\right.$, Lys ${ }^{40}(\mathrm{Ahx}-$ DOTA-68 $\mathrm{Ga}^{-} \mathrm{NH}_{2}$ ]-exendin-4 showed focal uptake on insulinoma (shown with the white arrow) (Courtesy of Dr. Kwadwo Antwi, University Hospital Basel).

\section{Exendin-4-based Radiopharmaceuticals}

The Glucagon-like peptide-1 receptor (GLP-1R) is a GPCR expressed in high incidence and density in benign insulinomas; an insulin-secreting neuroendocrine tumor of the pancreas. Insulinomas can cause life-threatening hypoglycaemia, with surgery being the only curative treatment. Preoperative localization of insulinomas is, therefore, essential but often very difficult due to their small size (between 1 and $2 \mathrm{~cm}$ ).

The natural ligand GLP-1 (30 amino acids) is unstable in vivo. Exendin-4 (H-His ${ }^{1}-\mathrm{Gly}^{2}-\mathrm{Glu}^{3}-\mathrm{Gly}^{4}-\mathrm{Thr}^{5}-\mathrm{Phe}^{6}-\mathrm{Thr}^{7}-\mathrm{Ser}^{8}-\mathrm{Asp}^{9}-$ Leu $^{10}-$ Ser $^{11}-$ Lys $^{12}-$ Gln $^{13}-$ Met $^{14}-$ Glu $^{15}-$ Glu $^{16}-$ Glu $^{17}-$ Ala $^{18}-$ Val $^{19}$ $\mathrm{Arg}^{20}-\mathrm{Leu}^{21}-\mathrm{Phe}^{22}-\mathrm{Ile}^{23}-\mathrm{Glu}^{24}-\mathrm{Trp}^{25}-\mathrm{Leu}^{26}-\mathrm{Lys}^{27}-\mathrm{Asn}^{28}-\mathrm{Gly}^{29}$ Gly $^{30}-$ Pro $^{31}-$ Ser $^{32}-$ Ser $^{33}-$ Gly $^{34}-$ Ala $^{35}-$ Pro $^{36}-$ Pro $^{37}-$ Pro $^{38}-$ Ser $^{39}-\mathrm{NH}_{2}$ ) is a metabolically resistant naturally occurring peptide identified in the saliva of the Gila monster lizard (Heloderma suspectum) that shares 53\% homology with the human GLP-1. Exenatide, synthetic exendin- 4 , is an antidiabetic medication for the treatment of type 2 diabetes mellitus (Byetta ${ }^{\circledR}$ ).

The well-defined secondary structure of exendin-4, with interaction of its $\mathrm{N}$-terminal with the receptor core domain and of the central helical region with the $\mathrm{N}$-terminal of the receptor, allow modification mainly at the C-terminal. In our institution, exendin- 4 was modified at the C-terminus by introducing $\mathrm{Lys}^{40}$, in the side chain of which the linker aminohexanoic acid (Ahx) followed by the chelator DTPA, and later on by DOTA, were coupled. $\left[\mathrm{Lys}^{40}\left(\mathrm{Ahx}-\mathrm{DTPA}-{ }^{111} \mathrm{In}\right) \mathrm{NH}_{2}\right]$-exendin-4 provided the first clinical evidence of the diagnostic value of GLP-1R imaging. [24] It was able to detected all insulinomas in patients with endogenous hyperinsulinemic hypoglycemia, which in addition were precisely localized intraoperatively using a $\gamma$-probe enabling their successful removal. ${ }^{[25]}$ A prospective multicentre study concluded that the higher sensitivity of GLP-1R imaging with $\left[\mathrm{Lys}^{40}(\mathrm{Ahx}-\right.$ DTPA- $\left.{ }^{111} \mathrm{In}\right) \mathrm{NH}_{2}$ ]-exendin-4 in comparison to CT or MRI for the detection of benign insulinoma was an improvement, changing the clinical management in a substantial percentage of patients. [26]

We replaced $\mathrm{Met}^{14}$ in this radiopharmaceutical by the nonoxidizing isosteric analogue $\mathrm{Nle}^{14}$ and conjugated DOTA for PET imaging with ${ }^{68} \mathrm{Ga}$. [ $\left[\mathrm{Nle}^{14}, \mathrm{Lys}^{40}(\mathrm{Ahx}-\mathrm{DOTA}) \mathrm{NH}_{2}\right]$-exendin-4 labeled with ${ }^{68} \mathrm{Ga}$ (and ${ }^{111} \mathrm{In}$ ) resulted in significantly higher radiochemical purity, compared to radiolabeled [Lys ${ }^{40}$ (Ahx-DOTA) $\mathrm{NH}_{2}$ ]-exendin-4. PET/CT imaging with $\left[\mathrm{Nle}^{14}{ }^{14} \mathrm{Lys}^{40}(\mathrm{Ahx}-\mathrm{DOTA}-\right.$ ${ }^{68} \mathrm{Ga}$ ) $\mathrm{NH}_{2}$ ]-exendin-4 (Fig. 3B) provided the highest diagnostic accuracy in the localization of benign insulinomas, as compared to SPECT/CT with $\left[\mathrm{Nle}^{14}\right.$ Lys $\left.^{40}\left(\mathrm{Ahx}-\mathrm{DOTA}-{ }^{111} \mathrm{In}\right) \mathrm{NH}_{2}\right]$-exendin-4 (including lower radiation burden and a shorter investigation time) and to MRI. ${ }^{[27,28]}$ In addition, $\left[\mathrm{Nle}^{14}{ }^{14} \mathrm{Lys}^{40}\left(\mathrm{Ahx}-\mathrm{DOTA}-{ }^{68} \mathrm{Ga}\right)\right.$ $\mathrm{NH}_{2}$ ]-exendin-4 PET/CT could localize hidden insulinomas, ${ }^{[28]}$ adult nesidioblastosis ${ }^{[29]}$ and detect insulinomas in patients with multiple endocrine neoplasia type-1 (MEN-1). ${ }^{[30]}$ It is worth mentioning that we are one of the very few centers worldwide offering this imaging modality to patients.

\section{Summary}

We are using peptides to develop targeted radiopharmaceuticals for imaging and therapy of oncological diseases. Our work includes peptide and chelation/bioconjugation chemistry, radiochemistry, in vitro studies in cell cultures and biological media, ex vivo studies in biological samples and in vivo evaluation in animal models, including imaging (SPECT/CT and PET/CT) and therapy studies. Our ultimate goal is the clinical translation of such radiopharmaceuticals, which is feasible in our institution due to the operation of a Good Manufacturing Practice (GMP) facility for the production of non-registered and first-in-man radiopharmaceuticals.

\section{Acknowledgements}

We thank the Swiss National Science Foundation, the Innosuisse (and former Commission of Technology and Innovation, Switzerland) and the University of Basel for financial support, and all our colleagues and collaborators involved in this work, whose names are acknowledged in the respective references.

Received: April 15, 2021

[1] R. T. Bass, B. L. Buckwalter, B. P. Patel, M. H. Pausch, L. A. Price, J. Strnad, J. R. Hadcock, Mol. Pharmacol. 1996, 50, 709 .

[2] S. J. Hocart, R. Jain, W. A. Murphy, J. E. Taylor, D. H. Coy, J. Med. Chem. 1999, 42, 1863, https://doi.org/10.1021/jm9806289

[3] R. Cescato, J. Erchegyi, B. Waser, V. Piccand, H. R. Maecke, J. E. Rivier, J. C. Reubi, J. Med. Chem. 2008, 51, 4030, https://doi.org/10.1021/jm701618q

[4] M. Ginj, H. Zhang, B. Waser, R. Cescato, D. Wild, X. Wang, J. Erchegyi, J. Rivier, H. R. Macke, J. C. Reubi, Proc. Natl. Acad. Sci. U S A 2006, 103, 16436, https://doi.org/10.1073/pnas.0607761103

[5] D. Wild, M. Fani, M. Behe, I. Brink, J. E. Rivier, J. C. Reubi, H. R. Maecke, W. A. Weber, J. Nucl. Med. 2011, 52, 1412, https://doi.org/10.2967/jnumed.111.088922

[6] R. Cescato, B. Waser, M. Fani, J. C. Reubi, J. Nucl. Med. 2011, 52, 1886, https://doi.org/10.2967/jnumed.111.095778

[7] X. Wang, M. Fani, S. Schulz, J. Rivier, J. C. Reubi, H. R. Maecke, Eur. J. Nucl. Med. Mol. Imaging 2012, 39, 1876, https://doi.org/10.1007/s00259-012-2231-8

[8] M. Fani, F. Braun, B. Waser, K. Beetschen, R. Cescato, J. Erchegyi, J. E. Rivier, W. A. Weber, H. R. Maecke, J. C. Reubi, J. Nucl. Med. 2012, 53, 1481, https://doi.org/10.2967/jnumed.112.102764

[9] M. Fani, L. Del Pozzo, K. Abiraj, R. Mansi, M. L. Tamma, R. Cescato, B. Waser, W. A. Weber, J. C. Reubi, H. R. Maecke, J. Nucl. Med. 2011, 52, 1110, https://doi.org/10.2967/jnumed.111.087999 
[10] G. P. Nicolas, R. Mansi, L. McDougall, J. Kaufmann, H. Bouterfa, D. Wild, M. Fani, J. Nucl. Med. 2017, 58, 1435, https://doi.org/10.2967/jnumed.117.191684

[11] R. Mansi, M. Fani, J. Labelled Comp. Radiopharm. 2019, 62, 635 , https://doi.org/10.1002/jlcr.3755

[12] G. P. Nicolas, S. Beykan, H. Bouterfa, J. Kaufmann, A. Bauman, M. Lassmann, J. C. Reubi, J. E. F. Rivier, H. R. Maecke, M. Fani, D. Wild, J. Nucl. Med. 2018, 59, 909, https://doi.org/10.2967/jnumed.117.199737

[13] G. P. Nicolas, N. Schreiter, F. Kaul, J. Uiters, H. Bouterfa, J. Kaufmann, T. E. Erlanger, R. Cathomas, E. Christ, M. Fani, D. Wild, J. Nucl. Med. 2018, 59, 915, https://doi.org/10.2967/jnumed.117.199760

[14] D. Wild, M. Fani, R. Fischer, L. Del Pozzo, F. Kaul, S. Krebs, R. Fischer, J. E. Rivier, J. C. Reubi, H. R. Maecke, W. A. Weber, J. Nucl. Med. 2014, 55, 1248, https://doi.org/10.2967/jnumed.114.138834

[15] R. P. Baum, J. Zhang, C. Schuchardt, D. Mueller, H. Maecke, J. Nucl. Med. 2021, 62, https://doi.org/10.2967/jnumed.120.258889

[16] L. Huo, W. Zhu, Y. Cheng, R. Jia, H. Zhao, C. Bai, J. Xu, S. Yao, J. Nucl. Med. 2021, 62, https://doi.org/10.2967/jnumed.120.253096

[17] R. H. Gaonkar, F. Wiesmann, L. Del Pozzo, L. McDougall, S. Zanger, R. Mikolajczak, R. Mansi, M. Fani, Pharmaceuticals (Basel) 2021, 14, 300 , https://doi.org/10.3390/ph14040300

[18] M. Fani, V. Weingaertner, P. Kolenc Peitl, R. Mansi, R. H. Gaonkar, P. Garnuszek, R. Mikolajczak, D. Novak, U. Simoncic, A. HubalewskaDydejczyk, C. Rangger, P. Kaeopookum, C. Decristoforo, Pharmaceuticals (Basel) 2021, 14, 19, https://doi.org/10.3390/ph14010019

[19] S. Good, M. A. Walter, B. Waser, X. Wang, J. Muller-Brand, M. P. Behe, J. C. Reubi, H. R. Maecke, Eur. J. Nucl. Med. Mol. Imaging 2008, 35, 1868, https://doi.org/10.1007/s00259-008-0803-4

[20] P. Kolenc-Peitl, R. Mansi, M. Tamma, T. Gmeiner-Stopar, M. SollnerDolenc, B. Waser, R. P. Baum, J. C. Reubi, H. R. Maecke, J. Med. Chem. 2011, 54, 2602, https://doi.org/10.1021/jm101279a

[21] P. Kolenc Peitl, M. Tamma, M. Kroselj, F. Braun, B. Waser, J. C. Reubi, M. Sollner Dolenc, H. R. Maecke, R. Mansi, Bioconjug. Chem. 2015, 26, 1113, https://doi.org/10.1021/acs.bioconjchem.5b00187

[22] A. W. Sauter, R. Mansi, U. Hassiepen, L. Muller, T. Panigada, S. Wiehr, A. M. Wild, S. Geistlich, M. Behe, C. Rottenburger, D. Wild, M. Fani, J. Nucl. Med. 2019, 60, 393, https://doi.org/10.2967/jnumed.118.207845
[23] C. Rottenburger, G. P. Nicolas, L. McDougall, F. Kaul, M. Cachovan, A. H. Vija, R. Schibli, S. Geistlich, A. Schumann, T. Rau, K. Glatz, M. Behe, E. R. Christ, D. Wild, J. Nucl. Med. 2020, 61, 520, https://doi.org/10.2967/jnumed.119.233031

[24] D. Wild, H. Macke, E. Christ, B. Gloor, J. C. Reubi, N. Engl. J. Med. 2008 359, 766, https://doi.org/10.1056/NEJMc0802045

[25] E. Christ, D. Wild, F. Forrer, M. Brandle, R. Sahli, T. Clerici, B. Gloor, F. Martius, H. Maecke, J. C. Reubi, J. Clin. Endocrinol. Metab. 2009, 94, 4398, https://doi.org/10.1210/jc.2009-1082

[26] E. Christ, D. Wild, S. Ederer, M. Behe, G. Nicolas, M. E. Caplin, M. Brandle, T. Clerici, S. Fischli, C. Stettler, P. J. Ell, J. Seufert, B. Gloor, A. Perren, J. C. Reubi, F. Forrer, Lancet Diabetes Endocrinol. 2013, 1, 115 https://doi.org/10.1016/S2213-8587(13)70049-4

[27] K. Antwi, M. Fani, T. Heye, G. Nicolas, C. Rottenburger, F Kaul, E. Merkle, C. J. Zech, D. Boll, D. R. Vogt, B. Gloor, E. Christ, D. Wild, Eur. J. Nucl. Med. Mol. Imaging 2018, 45, 2318, https://doi.org/10.1007/s00259-018-4101-5

[28] K. Antwi, M. Fani, G. Nicolas, C. Rottenburger, T. Heye, J. C. Reubi, B. Gloor, E. Christ, D. Wild, J. Nucl. Med. 2015, 56, 1075 , https://doi.org/10.2967/jnumed.115.157768

[29] E. Christ, D. Wild, K. Antwi, B. Waser, M. Fani, S. Schwanda, T. Heye, C. Schmid, H. U. Baer, A. Perren, J. C. Reubi, Endocrine 2015, 50, 821 , https://doi.org/10.1007/s12020-015-0633-7

[30] K. Antwi, G. Nicolas, M. Fani, T. Heye, F. Pattou, A. Grossman, P. Chanson, J. C. Reubi, A. Perren, B. Gloor, D. R. Vogt, D. Wild, E. Christ, J. Clin Endocrinol. Metab. 2019, 104, 5843, https://doi.org/10.1210/jc.2018-02754

\section{License and Terms}

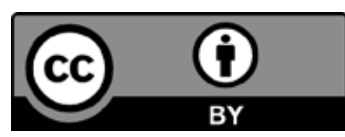

This is an Open Access article under the terms of the Creative Commons Attribution License CC BY 4.0. The material may not be used for commercial purposes.

The license is subject to the CHIMIA terms and conditions: (http:// chimia.ch/component/sppagebuilder/?view=page\&id=12).

The definitive version of this article is the electronic one that can be found at https://doi.org/10.2533/chimia.2021.500 